\title{
A fuzzy multi-criteria decision making model for construction contractor prequalification
}

\author{
Ana Nieto-Morote ${ }^{a, *}$, Francisco Ruz-Vila ${ }^{b}$ \\ a Project Engineering Department, Technical University of Cartagena (UPCT), c/Dr. Fleming, s/n, \\ 30202 Cartagena, Spain \\ ${ }^{\mathrm{b}}$ Electrical Engineering Department, Technical University of Cartagena (UPCT), c/Dr. Fleming, s/n, \\ 30202 Cartagena, Spain
}

Please cite this article in press as: Nieto-Morote, A, Ruz-Vila, F, A fuzzy multi-criteria decision making model for construction contractor prequalification, Automation in Construction, 25 (2012) 8-19.

doi: $10.1016 / j$.autcon.2012.04.004

\begin{abstract}
Selecting an appropriate contractor is essential for the success of any construction project. Contractor prequalification procedure makes it possible to admit for tendering only competent contractor. Prequalification is a multi-criteria decision problem that is, in essence, largely dependent on the uncertainty and vagueness in the nature of construction projects and subjective judgement of the decision-maker. This paper presents a systematic prequalification procedure, based on Fuzzy Set Theory, whose main differences and advantages in comparison with other models are the use of an algorithm to handle the inconsistencies in the fuzzy preference relation when pair-wise comparison judgements are used and the use of linguistic assessment or exact assessment of performance of the contractors on qualitative or quantitative criterion, respectively. Finally, a case study for the rehabilitation project of a building at Technical University of Cartagena is presented to illustrate the use of the proposed model and to demonstrate its effectiveness.
\end{abstract}

Keywords: Contractor prequalification, Multi-criteria decision making, Linguistic variable, Techniques for order preference by similarity to ideal solution (TOPSIS).

\section{Introduction}

The complexity and adversity of the current construction industry aggravate the various risks and uncertainties faced by contractors, which influence their ultimate performance levels. The adequate selection of suitable contractors is directly related to construction project success and the achievement of specified objectives, therefore contractor selection constitutes a critical decision for any project manager [1,2].

Several pre-selection procedures such as open tendering, selective/restricted tendering, prequalification or negotiation are currently practiced for contractor selection [3]. In an open tendering process every contractor can apply and after a bids evaluation process, the optimal bid is awarded the contract. When a construction contract involves special expertise and high technology, the adequate selection process is selective or restricted tendering because only the contractors who fulfil project requirements can apply for this procedure. Prequalification is the process of screening contractors where the capabilities below which contractors will be considered are established. Finally, when the contract is too complex, or there is an emergency situation, or when no application is made for the other mentioned procedures a negotiation procedure is implemented.

\footnotetext{
* Corresponding autor. Tel: + 34968 326551; fax: + 34968326400.

E-mail address: ana.nieto@upct.es
} 
Traditionally, one of the most frequently procedures used for selecting contractors has been open tendering where the lowest bidder is awarded the contract [4]. However, the lowest bidder is not always the most economic choice in the long term as the client runs the risk of poor performance by that contractor during the project life. In seeking to minimise the aforesaid risks and failures and to enhance the performance levels of contractors a process to evaluate candidate contractors' ability to complete a contract satisfactorily before they are admitted into the bidding process is often applied [5].

Several specific characteristics of the prequalification problem should be taken into account in order to obtain good results in the application of any prequalification model. These critical characteristics are [6]:

1. Prequalification is a multi-criteria problem. The proposed model should do analysis of the criteria on a simultaneous basis.

2. Prequalification contains risks inherited from different decision maker's opinion.

3. Prequalification includes uncertain date given by different contractors.

4. Prequalification contain subjective judgement made by decision makers.

5. Prequalification include nonlinear relationships between contractor's attributes and their corresponding prequalification decisions.

6. The model should be able to adapt the results to suite changes associated between different contractors.

7. It should be able to deal with qualitative as well as quantitative.

\section{Contractor prequalification models}

Contractor prequalification can be regarded as a multi-criteria problem: potential contractors are measured and judged in accordance with a set of criteria. Many multi-criteria techniques are proposed and applied for this problem solution such as multi-criteria decision making (MCDM) [7-9], multi-attribute analysis (MAA)[10, 11], multi-attribute utility theory (MAUT) [4, 12], case-based reasoning (CBR) [13, 14], cluster analysis (CA)[15] and graph theory (GT)[16]. However, most of these models are based on rather simplistic perceptions of the problem and they have important limitations when real-life contractor prequalification problems are handled.

Contractor prequalification often involves much inexact, uncertain and incomplete information therefore it is very difficult to measure, especially, the judgments and preferences of decision makers. The uncertainty is due mainly to the fuzziness and randomness associated with contractor performance, decision-maker experience, prequalification criteria and the qualitative judgements. These substantial uncertainties and subjectivities have hampered the applicability of many methods which have been used widely in prequalification problems and require high quality data.

Recently, some contractor prequalification approaches have been based on using linguistic assessments instead of numerical values. Fuzzy Set Theory [17] provides a useful tool to deal with decisions in which the phenomena are imprecise and vague, it enables to qualify imprecise information, to reason and make decisions based on vague and incomplete data [18]. This allows incorporating qualitative factors into decision making problems.

Fuzzy sets were for the first time used to build a contractor selection model by Nguyen [19]. He proposed a procedure of choosing a bidder taking into consideration 3 criteria: cost, presentation of bid information and past experience, as well as different scenarios of a construction owner's preferences.

A fuzzy neural network (FNN) model, amalgamating both the fuzzy set and artificial neural network theories, was developed by Lam [20] aiming to improve the objectiveness of contractor prequalification. Through FNN theory, the fuzzy rules as used by the decision makers can be identified and the membership functions by utilizing neural networks' learning capability can be tuned.

Singh and Tiong [21] presented a model which allows taking into consideration different types of criteria and characterizing them as sub-criteria, where the notion of Shapley value is used to determine relative importance of each criteria, and linguistic variables based on fuzzy numbers theory is constructed for decision makers to evaluate the contractor's attributes. It 
admits subjective evaluations of numerous decision-makers. Decision-makers can use linguistic variables both for the criteria and for the degree of satisfying them by contractors.

Li [22] proposed a fuzzy framework to solve construction contractor prequalification problems that takes full advantage of the experts' knowledge, experiences, and makes the decision-maker feels comfortable to give judgment on prequalification issue. The framework includes decision criteria analysis, weights assessment, and ranking orders determination of contractors. Relative importance of criteria and evaluation of criteria assigned by decisionmakers are expressed in linguistic variables and then a fuzzy arithmetical operation is employed to aggregate the fuzzy numbers into the final decisions. Once final fuzzy assessment of contractors have been obtained, four approaches, i.e., fuzzy number recognition (FNR) method, fuzzy TOPSIS (FT) method, fuzzy number weight center (FNWC) method, and simple defuzzification method are applied to rank contractors.

Plebankiewicz [23] presented a fuzzy model which takes into consideration both different criteria of contractor evaluation and the objectives the construction owner wants to achieve in the project. In the model, the elements of the fuzzy relation determine the relationship between objective $c$ and contractor $w$ through their respective relationships to criterion $k$. The construction owner has possibility to express his evaluation concerning the criteria weight, objectives and also satisfying the criteria by the contractors, using linguistic variables. Owing to the application of Fuzzy Set Theory, these variables are converted into a fuzzy numbers. In order to avoid a rather complicated mathematical apparatus the author worked in the proposal of a computer program supporting the prequalification procedure process.

Juan [24] proposed a hybrid approach combining Fuzzy Set Theory and quality function deployment (QFD) to establish a contractor selection model. The whole fuzzy-QFD process include five steps for determining the weights of client's requirements and criteria: (i) Identify client's requirements (WHATs), (ii) Determine contractor selection criteria (HOWs) (iii) Compute the weights of WHATs based on client's requirements; (iv) Build a relation matrix between WHATs and HOWs obtained, (v) Compute the weights of HOWs based on relation matrix; and other two steps for evaluating the contractor ranks: (vi) Assess tender characteristics obtained from each contractor's service or specifications; (vii) Rank potential contractors according to their performance.

This paper presents a proposal of a fuzzy contractor prequalification approach whose main differences and advantages in comparison with previous ones are the use of an algorithm to handle the inconsistencies in the fuzzy preference relation when pair-wise comparison judgements are necessary and the use of linguistic assessment and exact assessment of performance of the contractors on qualitative criterion and quantitative criterion, respectively.

\section{Criteria of contractors' prequalification}

A crucial task in contractor prequalification process is to establish a set of decision criteria through which the capabilities of contractors are measured and judged. [25]

For contractor prequalification, a wide variety of criteria have been proposed $[4,10,22,23$, 26]. Criteria for prequalification may vary between projects since the characteristics of them are distinct although there are some common characteristics of contractor prequalification. All the projects have a reasonable cost, require a reasonable quality, within a reasonable time and with reasonable security [29].

Due to this, the most common criteria considered during the prequalification are those related with the following aspects:

1. Technical capacity. The contractor must demonstrate that it has the technical capacity to perform the activities of the specific project for which it is seeking the prequalification.

2. Experience: The contractor must demonstrate its participation in other previous projects, especially if they are similar to the project that will be executed.

3. Management capability. The contractor must demonstrate that it is capable of planning, organizing and controlling a project.

4. Financial stability. The client must reach an informed opinion regarding the overall financial position and capability of contractor. 
5. Past performance: Considering the past performance of each contractor, the project manager will have a higher or lower degree of confidence in the possible contractors regarding the quality, time and cost control requirements

6. Occupational health and safety. To encourage contactors to establish and maintain effective systems to manage the risks to the health and safety of their employees, arising from the nature of the work

To be more efficiently assessed, the main criteria above defined must be decomposed into sub-criteria. Without wishing to be exhaustive because sub-criteria can be different depending on the project nature, a basic decomposition of criteria into sub-criteria is shown in Table 1.

Table 1

Main Criteria and Sub-criteria for Contractor Prequalification

\begin{tabular}{ll}
\hline Criteria & Sub-criteria \\
\hline Technical capacity & 1. Qualification of staff \\
& 2. Experience of staff \\
& 3. Innovate method \\
4. Labor and equipment \\
1. Type of past project completed \\
2. Size of past project completed \\
3. Number of projects completed \\
4. Experience in local area \\
1. Organisational culture \\
2. Management knowledge \\
3anagement ability & 1. Quality policy \\
& 2. Projects completed on time \\
Past Performance & 3. Projects completed on budget \\
& 1. Financial soundness \\
Financial stability & 2. Credit ranting \\
& 3. Liquidity \\
Occupational health and safety & 1. Management safety accountability \\
& 2. Safety performance
\end{tabular}

\section{Linguistic variable.}

A linguistic variable is a variable whose values are words or sentences in a natural language [18]. For example, if a linguistic variable is defined as the performance of a goal-oriented entity, its values can be represented by linguistics terms such as very small, small, medium, large and very large. The values defined for a linguistic variable will obviously depend on the problem context.

In those decision-making problems, in which it is relatively difficult to provide exact numerical values for the variables decision due to the availability and uncertainty of information, the concept of linguistic variables play a fundamental role. In these cases, the decision-maker prefers a linguistic assessment instead of an exact numerical assessment due to great subjectivity, imprecision and vagueness involved.

Since linguistic terms are not mathematically operable, to cope with this difficulty, each linguistic term is associated with a fuzzy number, which represents the meaning of each generic verbal term. Normally, the trapezoidal or triangular fuzzy numbers are most common in current applications [30] because they have more intuitive and more natural interpretation than fuzzy number with irregular shapes and calculations are less complicated.

\subsection{Fuzzy set and fuzzy numbers}

The Fuzzy Set Theory introduced by Zadeh [17] is suitable for dealing with imprecision and uncertainty associated with data in decision problems. In a universal set of discourse $X$, a fuzzy subset $A$ of $X$ is defined by a membership function $\mu_{A}(x)$, which maps each element $x$ in $X$ to a 
real number in the interval $[0,1]$. The function value of $\mu_{A}(x)$ signifies the grade of membership of $x$ in $A$. When $\mu_{A}(x)$ is large, its grade of membership of $x$ in $A$ is strong.

Among the various types of fuzzy sets of special significance are fuzzy numbers [31] defined as $A=\left\{x, \mu_{A}(x)\right\}$ where $x$ takes its number on the real line $\mathbb{R}$ and membership function $\mu_{A}: \mathbb{R} \rightarrow[0$, 1], which have the following characteristics [32]: (i) Constant on $(-\infty, a]$ and $[d, \infty): \mu_{A}(x)=0 \forall$ $x \in(-\infty, a] U[d, \infty)$; (ii) Strictly increasing on $[a, b]$ and strictly decreasing on $[c, d]$; and (iii) Constant on $[b, c]: \mu_{A}(x)=1 \forall x \in[b, c]$, where $a, b, c, d$ are real numbers and eventually $a=$ $\infty$, or $b=c$, or $a=b$, or $c=d$ or $d=\infty$.

For convenience, ${ }^{L} \mu_{A}$ is named as left membership function of a fuzzy number $A$, defining ${ }^{L} \mu_{A(x)}=\mu_{A}(x), \forall x \in[a, b] ;{ }^{R} \mu_{A}$ is named as right membership function of a fuzzy number $A$, defining ${ }^{R} \mu_{A}(x)=\mu_{A}(x), \forall x \in[c, d]$.

A trapezoidal fuzzy number A is a fuzzy number denoted as $A=(a, b, c, d)$ which membership function is defined as:

$\mu_{A}(x)=\left[\begin{array}{cl}0 & \text { for } x<a \\ { }^{L} \mu_{A}(x)=\frac{x-a}{b-a} & \text { for } a \leq x \leq b \\ 1 & \text { for } b \leq x \leq c \\ { }^{R} \mu_{A}(x)=\frac{x-d}{c-d} & \text { for } c \leq x \leq d \\ 0 & \text { for otherwise }\end{array}\right.$

where $a, b, c, d$ are real numbers and $a<b<c<d$. If $b=c$, it is defined a triangular fuzzy number.

\section{Research methodology}

A decision model for contractor prequalification based on Fuzzy Set Theory is offered in this paper. The model involves a multi-criteria evaluation of contractors and the establishment of a classification of all the feasible contractors. The conceptual stages of contractor prequalification are shown in the model presented in Fig. 1. 


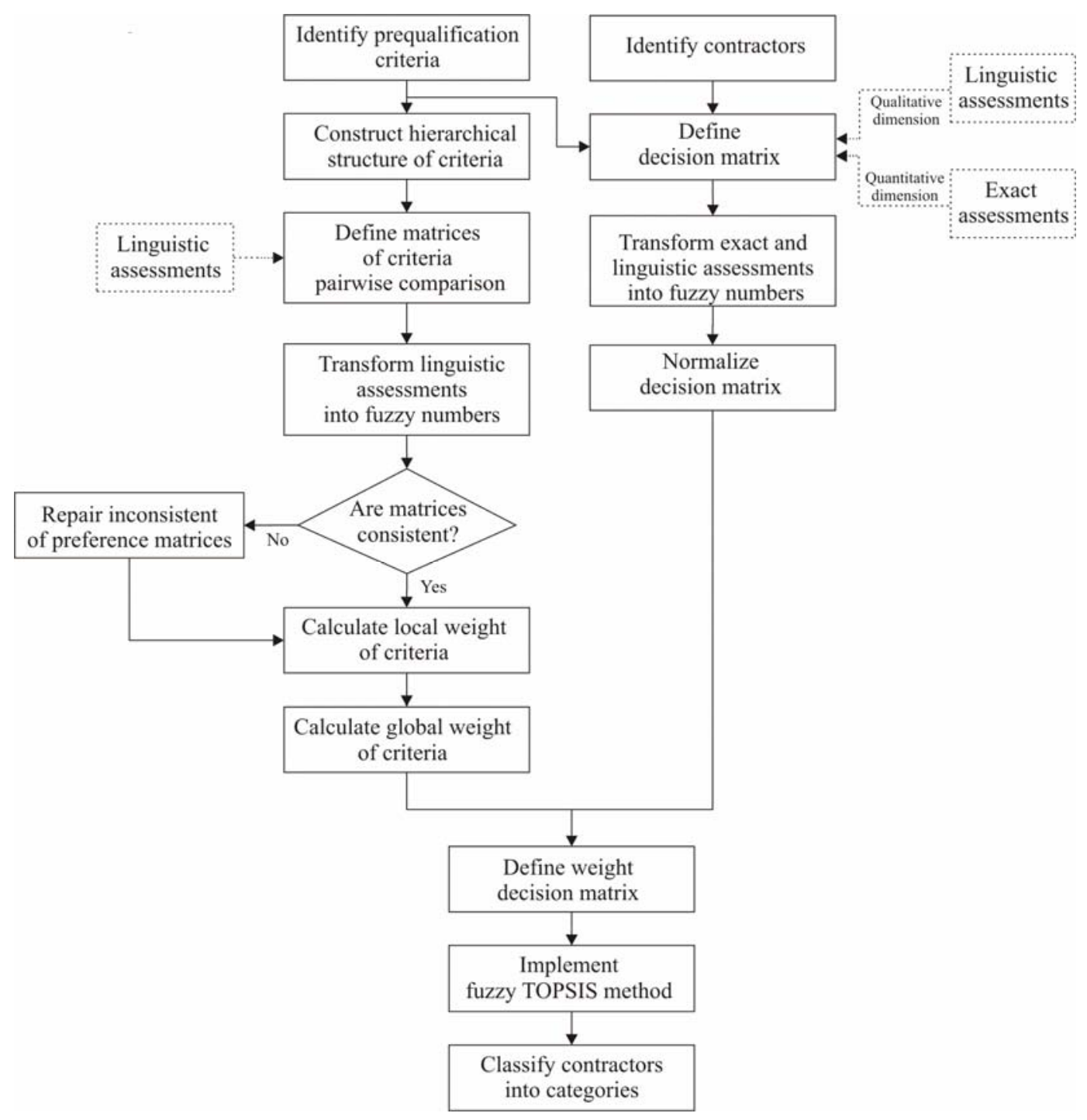

Fig. 1. Stepwise procedure

At the first stage, a set of criteria for evaluating the potential contactors is established by taking into account the nature of construction project. The establishment of a proper evaluation criteria system is basic for an adequate classification of contractors, therefore, decision criteria must be reflected the project objectives, the needs of the clients and all the factors that influence the adequate project performance. To be efficiently assessed, decision criteria are decomposed into sub-criteria and a hierarchical structure of criteria is generated.

In many decision problems, decision criteria have not the same importance so a weight which represents its importance is assigned to each criterion. With a hierarchical structure of criteria, each criterion is associated with a local weight and a global weight. The local weight of a criterion is referred to the weight relative to other criteria at the same group and level, which is to be assessed using the pair-wise comparison process. The global weight of a criterion is referred to the weight relative to all other criteria for the overall objective of the decision problem.

To calculate the local weight of each criterion, experts are required to provide their comparative judgement on the relative importance of one criterion on other, belonging both to the same level and group in the hierarchical structure.

The pair-wise comparison usually involves much inexact, uncertain or incomplete information that is very difficult to measure the judgements and preferences of decision-maker. In this environment, based on Fuzzy Set Theory, assessments are described subjectively in linguistic terms such as "more important", "equally important", etc. An appropriate standard 
linguistic variable set is built to help expert to assess the relative importance of criteria pairwise. Since linguistic terms are not mathematically operable, to cope with this difficulty, each linguistic term is associated with a fuzzy number, which represents the meaning of each generic verbal term. This representation does not only depend on the concept but also on the context in which it is used. Even for similar contexts, fuzzy numbers representing the same concept may vary considerably therefore it must be carefully defined in accordance with the characteristics of the project.

Generally, the preference information about criteria expressed as a fuzzy preference relation presents inconsistency problems. The lack of consistency in the pair-wise criteria comparison matrices can lead to inconsistent set of local weights of criteria therefore a method in order to get a minimum consistency must be applied. The most of the research studies $[6,29]$ which apply the concepts of Analytic Hierarchy Process (AHP) determine if the comparison matrix is consistent or not by calculating the consistency ratio. If matrix is not consistent experts must reevaluate the relative importance of each pair of criteria therefore the expert's judgements are modified.

In this paper, other concepts are applied to handle with the inconsistency problem of the preference matrices. Since the preference information between criteria $C_{i}$ and $C_{j}, v_{i j}{ }_{i j}$, can also be reflected in their ranking values $w_{i}$ and $w_{j}$, there exists an explicit function relation between $v^{\prime}{ }_{i j}$ and $w_{i}$ and $w_{j}$ defined as $v_{i j}^{\prime}=0.5 \times\left[1+\psi\left(w_{i}\right)-\psi\left(w_{j}\right)\right]$ where $\psi\left(w_{i}\right)$ can be any non-decreasing function [33]. In order to keep the simplicity of the method, if $\psi\left(w_{i}\right)=w_{i}$ then $v_{i j}^{\prime}=0.5 \times\left[1+w_{i}-w_{j}\right]$.

Weak transitivity, i.e. $v_{i k} \geq 0.5$ for $v_{i j} \geq 0.5$ and $v_{j k} \geq 0.5$, is the property that is usually accepted to deal with problems of fuzzy preference relations consistency [34, 35]. Due to the fuzziness of the opinions and the weak transitivity restriction considered, an accurate solution for this problem could not be found [36]. By the extension of this classical method to a fuzzy method, the $w_{i}$ and $w_{j}$ values are calculated by difference minimization method of the value $v_{i j}$, obtained directly from the experts, and the value $v{ }^{\prime} i j$, defined as a ideal fuzzy preference relations which are consistent.

$$
\min \left[\sum_{\mathrm{i}=1}^{\mathrm{n}} \sum_{\substack{\mathrm{j}=1 \\ \mathrm{i}=1}}^{\mathrm{n}}\left(v_{{ }_{\mathrm{ij}}} \Theta v_{\mathrm{ij}}\right)^{2}\right]
$$

where $v^{\prime}{ }^{\prime}$ ij is defined as:

$$
v^{\prime}{ }_{i j}=\frac{w_{i} \oplus\left(1 \Theta w_{j}\right)}{2}
$$

where $i$ and $j$ are criteria of group $g$ and level $l$ and $\oplus$ and $\Theta$ represents fuzzy addition and subtraction defined in Eqs. (A4) and (A5), respectively.

Once local weight of all criteria, $w_{i}$, are calculated, the global weight, $W_{i}$, of each criteria at the bottom level of the hierarchy is calculated as

$$
\mathrm{W}_{\mathrm{i}}=\mathrm{w}_{\mathrm{i}} \otimes \prod_{\mathrm{j}=1}^{\mathrm{t}} \mathrm{w}_{\text {group }}^{(\mathrm{j})}
$$

where $i$ is each one of the criteria at the lowest level of the hierarchy, $t$ is the upper groups at different level in the criteria hierarchy, $w^{(j)}$ group is the group weight of the $j^{\text {th }}$ upper group which contain the criterion $C_{i}$ in the hierarchy and $\otimes$ represents fuzzy multiplication defined in Eq.(A6).

Another important and crucial task is to evaluate the rating of the contractor with respect to each evaluation criterion, i.e., to define the decision-making matrix, especially when evaluation criteria may have quantitative and qualitative dimensions. When the evaluation criterion is qualitative, most of the times, the decision-maker is not capable of defining in a strict way how good the contractor is, with regard to this criterion. In these situations, the decision-maker prefers assessments that are not exact but approximate and which are adjusted to the reality. Therefore, in these cases, in general, it is preferable for the decision-makers to evaluate their judgments by means of linguistic terms instead of real numbers. Therefore, two types of 
assessments are proposed: (i) when the evaluation criterion is quantitative, assessment are real numbers, and (ii) when evaluation criterion is qualitative, assessment are linguistic terms.

In the same way that linguistic assessments on the relative importance of pair of criteria are transformed into fuzzy numbers, the linguistic ratings of the contractors with respect to qualitative evaluation criteria are transformed into corresponding fuzzy numbers. Although "a priori" it seems no-sense the fuzzification of an exact value, to operate mathematically it is necessary to convert assessment in terms of real numbers into fuzzy number as well.

To define adequately the decision-making matrix, two aspects have to be considered: (i) the evaluation criteria are their own characteristics and each one of criteria data has their own dimension and distribution and (ii) the evaluation criterion have different importance on the final decision.

When each one of criteria data has their own dimension and distribution, it is difficult to directly compare or operate. As result, the original data of criteria evaluation should be dimensionless and unit-free by normalization method. The normalized fuzzy decision matrix can be represented as $\breve{\mathrm{G}}=\left[\breve{\mathrm{G}}_{\mathrm{ij}}\right]$ and its elements defined as:

$$
\breve{G}_{i j}=\frac{G_{i j}}{G_{j}^{+}}=\left(\frac{g_{i j}^{a}}{g_{j}^{d+}}, \frac{g_{i j}^{b}}{g_{j}^{c+}}, \frac{g_{i j}^{c}}{g_{j}^{b+}}, \frac{g_{i j}^{d}}{g_{j}^{a+}} \wedge 1\right)
$$

where

$$
\mathrm{G}_{\mathrm{j}}^{+}=\max \left\{\mathrm{G}_{\mathrm{ij}} \mid \mathrm{i}=1,2, \ldots, \mathrm{m}\right\}=\left(\mathrm{g}_{\mathrm{j}}^{\mathrm{a}+}, \mathrm{g}_{\mathrm{j}}^{\mathrm{b}+}, \mathrm{g}_{\mathrm{j}}^{\mathrm{c}+}, \mathrm{g}_{\mathrm{j}}^{\mathrm{d}+}\right)
$$

when criterion $\mathrm{C}_{\mathrm{j}}$ is a benefit item; or as

$$
\breve{G}_{i j}=\frac{G_{j}^{-}}{G_{i j}}=\left(\frac{g_{j}^{a-}}{g_{i j}^{d}}, \frac{g_{j}^{b-}}{g_{i j}^{c}}, \frac{g_{j}^{c-}}{g_{i j}^{b}}, \frac{g_{j}^{d-}}{g_{i j}^{a}} \wedge 1\right)
$$

where

$$
\mathrm{G}_{\mathrm{j}}^{-}=\min \left\{\mathrm{G}_{\mathrm{ij}} \mid \mathrm{i}=1,2, \ldots, \mathrm{m}\right\}=\left(\mathrm{g}_{\mathrm{j}}^{\mathrm{a}-}, \mathrm{g}_{\mathrm{j}}^{\mathrm{b}-}, \mathrm{g}_{\mathrm{j}}^{\mathrm{c}-}, \mathrm{g}_{\mathrm{j}}^{\mathrm{d}-}\right)
$$

when criterion $\mathrm{C}_{\mathrm{j}}$ is a cost item.

On the other hand, when criteria have not the same importance the rating of the contractor with respect each criterion must be recalculate by means of the multiplication of the original rating by the criteria weight.

By taking into account these two considerations, the weighted-normalized decision-making matrix is defined as:

$\mathrm{V}_{\mathrm{ij}}=\breve{\mathrm{G}}_{\mathrm{ij}} \otimes \mathrm{W}_{\mathrm{j}} \quad \mathrm{i}=1,2, \ldots, \mathrm{m} ; \mathrm{j}=1,2, . . \mathrm{n}$

where $W_{j}$ is the weight of criteria $C_{j}, \breve{G}_{i j}$ are the elements of normalized decision-making matrix and $\otimes$ represents the fuzzy multiplication defined in Eq. (A6).

Finally, Technique for Order Performance by Similarity to Ideal Solution (TOPSIS) method [37] may provide the basis for classifying contractors. This method is based on the concept that the best alternative should have the shorter distance from the Positive Ideal Solution $(P I S)$ and the farthest from the Negative Ideal Solution (NIS). For each contactor a closeness coefficient $(C C)$ is calculated as:

$$
\mathrm{CC}_{\mathrm{i}}=\frac{\mathrm{d}_{\mathrm{i}} *}{\mathrm{~d}_{\mathrm{i}} *+\mathrm{d}_{\mathrm{i}}{ }^{-}}
$$

where $d_{i}{ }^{*}$ is the distance of each contractor from PIS and $d_{i}^{-}$is the distance of each contractor from NIS defined as:

$$
\begin{aligned}
& \mathrm{d}_{\mathrm{i}} *=\sum_{j=1}^{n} \mathrm{~d}_{v}\left(\mathrm{~V}_{i j}, \mathrm{~V}_{j}^{*}\right), \mathrm{i}=1,2, \cdots, \mathrm{m} \\
& d_{\mathrm{i}}{ }^{-}=\sum_{j=1}^{n} \mathrm{~d}_{\mathrm{v}}\left(\mathrm{V}_{i j}, \mathrm{~V}_{j}^{-}\right), \mathrm{i}=1,2, \cdots, \mathrm{m}
\end{aligned}
$$


where $d_{v}($; ) is the distance measurement between two fuzzy numbers defined in Eq. (A8) and

$$
\begin{aligned}
& \text { PIS }=\left(V_{1}{ }^{*}, V_{2}{ }^{*}, \ldots, V_{n}{ }^{*}\right) \text {, where } V_{i}{ }^{*}=\left(\max _{m} V_{i j}, i \in J_{1} ; \min _{m} V_{i j}, i \in J_{2}\right) \\
& N I S=\left(\mathrm{V}_{1}^{-}, \mathrm{V}_{2}{ }^{-}, \ldots, \mathrm{V}_{n}{ }^{-}\right) \text {, where } V_{\mathrm{i}}^{-}=\left(\min _{\mathrm{m}} \mathrm{V}_{\mathrm{ij}}, \mathrm{i} \in \mathrm{J}_{1} ; \max _{\mathrm{m}} \mathrm{V}_{\mathrm{ij}}, \mathrm{i} \in \mathrm{J}_{2}\right)
\end{aligned}
$$

where $J_{1}$ and $J_{2}$ are the sets of benefit criteria and cost criteria, respectively.

According to descending order of $C C$, the ranking order of all contractors can be determined, although a more realistic approach may be to use a linguistic variable to describe the current assessment status of each contractor in accordance with its closeness coefficient. The interval $[0,1]$ is divided into certain sub-intervals which are corresponded with each one of the proposed assessment status that may be "Do not recommended", "Recommended with risk" and "Approved".

\section{Case study}

The project manager of the rehabilitation project of a building at Technical University of Cartagena, shown in Fig. 2, wanted to make a list of contractors able to realize this project. To do this he had to evaluate five contractors (A, B, C, D, E).

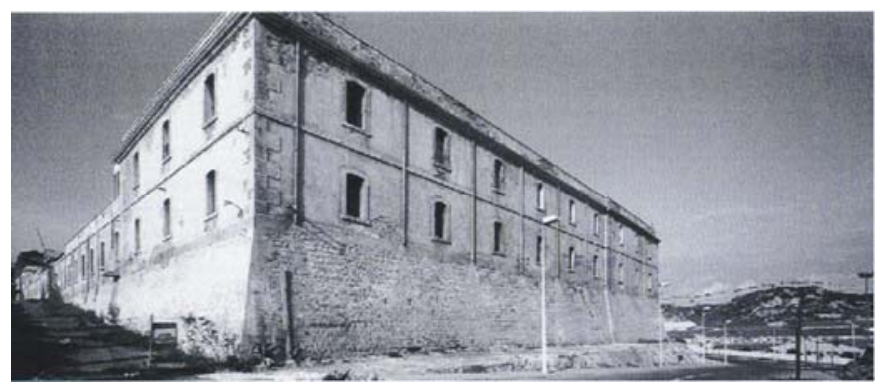

Fig. 2. University building to be rehabilitated

According to some contractor selection literature, an in-depth discussion to identify the appropriate contractor prequalification criteria was conducted by experienced project manager team. The most relevant criteria included technical capacity, experience, management capability, past performance, financial capability and occupational health and safety. These criteria were decomposed into sub-criteria as shown in Fig. 3. Table 2 presents a description of each second-level criterion. 


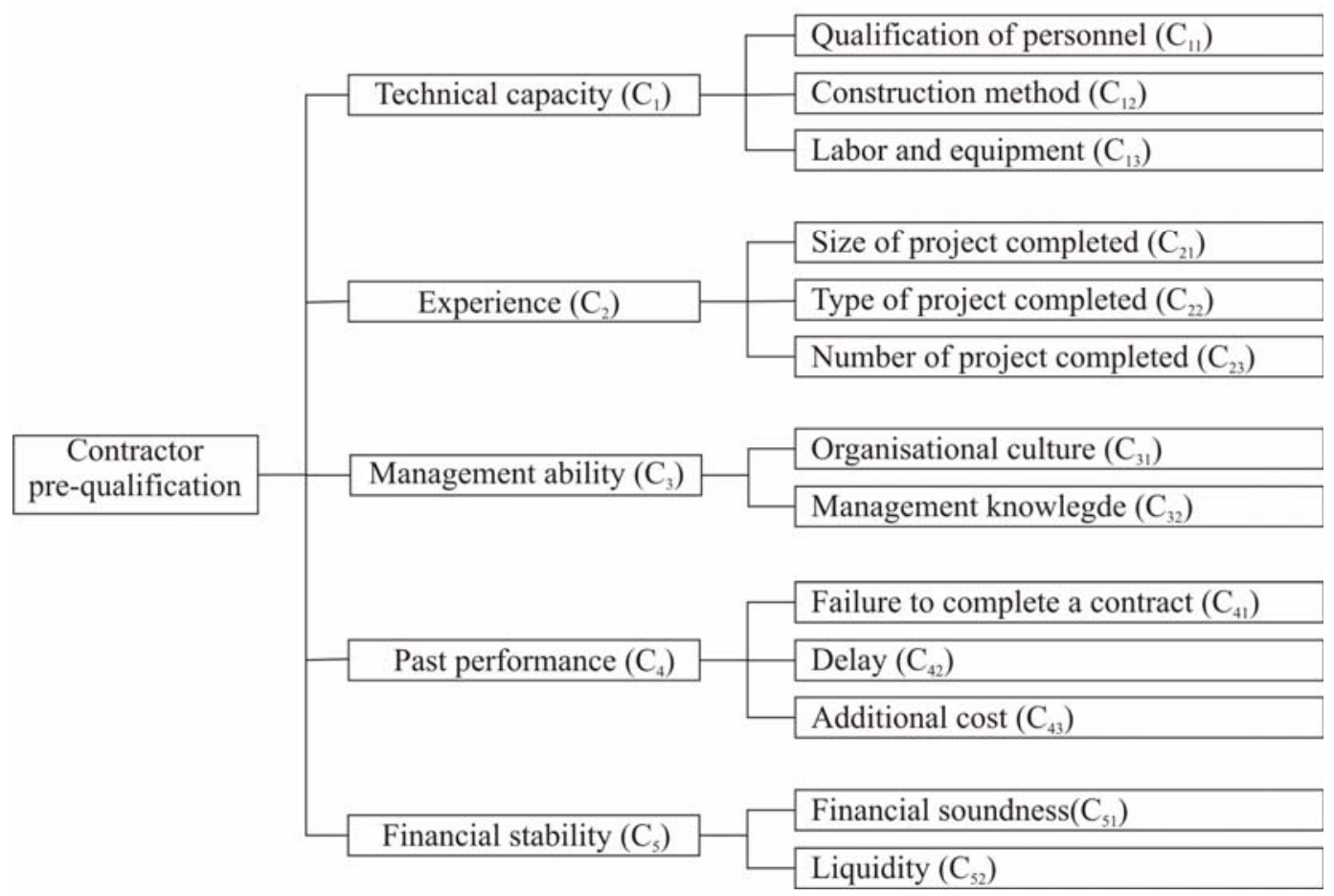

Fig. 3. Hierarchical structure of criteria

Table 2

Description of decision criteria

\begin{tabular}{|c|c|c|}
\hline Sub-criteria & Description & Dimension \\
\hline Qualification of personnel & Degree and professional status of personnel & Qualitative \\
\hline Construction method & $\begin{array}{l}\text { Whether construction technologies and processes are adequate } \\
\text { or not }\end{array}$ & Qualitative \\
\hline Labor and equipment & $\begin{array}{l}\text { Whether human resources and equipment are enough to } \\
\text { execute the project or not }\end{array}$ & Qualitative \\
\hline Size of projects completed & Size of projects executed within the last 5 years & Qualitative \\
\hline Type of projects completed & $\begin{array}{l}\text { Whether projects executed within the last } 5 \text { years are similar to } \\
\text { the project or not }\end{array}$ & Qualitative \\
\hline Number of projects completed & Number of projects executed within the last 5 years & Quantitative \\
\hline Organizational culture & $\begin{array}{l}\text { Whether contractor has specific collection of values and norms } \\
\text { that are shared by personnel or not }\end{array}$ & Qualitative \\
\hline Management knowledge & $\begin{array}{l}\text { Whether strategies and practices used in the organization are } \\
\text { adequate or not }\end{array}$ & Qualitative \\
\hline Failure to complete a contract & $\begin{array}{l}\text { Number of project executed without failure to achieve } \\
\text { termination within the last } 5 \text { year }\end{array}$ & Quantitative \\
\hline Delay & Number of project executed on time within the last 5 year & Quantitative \\
\hline Additional cost & Number of project executed on budget within the last 5 year & Quantitative \\
\hline Financial soundness & Whether contract has financial health or not & Qualitative \\
\hline Liquidity & Sum of contractor's cash & Quantitative \\
\hline
\end{tabular}

Once decision criteria and possible candidates are identified, the computational procedure of the proposed method is summarized as follows: 
Step 1. To define matrices of criteria pair-wise comparison, seven linguistic terms to express decision maker's opinion on the relative importance of each pair of criteria are used. These linguistic variables are "absolutely less important (AL), "strongly less important (SL)", "weakly less important (WL)", "equally important (E)", "weakly more important (WM)", "strongly more important (SM)" and "absolutely more important (AM)" whose corresponding fuzzy numbers are shown in Table 3 and Fig. 4.

Table 3

Linguistic scale for criteria relative importance

\begin{tabular}{ll}
\hline Linguistic set & Fuzzy number \\
\hline Absolutely less important (AL) & $(0,0,0.1)$ \\
Strongly less important (SL) & $(0,0.15,0.3)$ \\
Weakly less important (WL) & $(0.1,0.3 .0 .5)$ \\
Equally important (E) & $(0.3,0.5,0.7)$ \\
Weakly more important (WM) & $(0.5,0.7,0.9)$ \\
Strongly more important (SM) & $(0.7,0.85,1.0)$ \\
Absolutely more important (AM) & $(0.9,1.0,1.0)$ \\
\hline
\end{tabular}

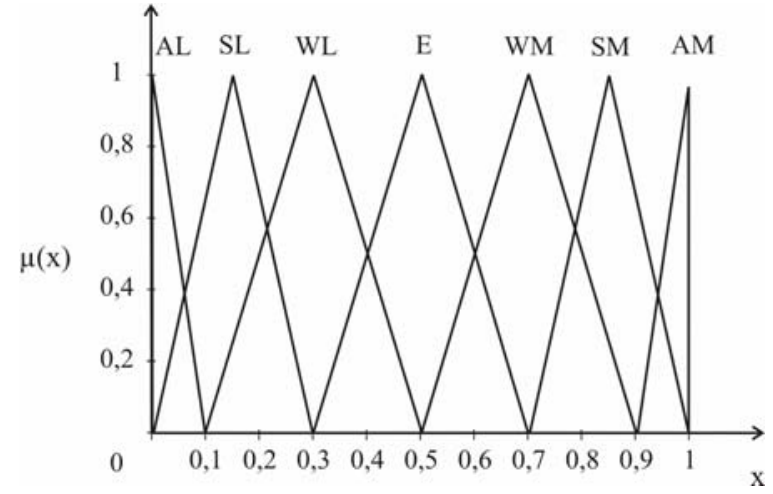

Fig. 4. Graphical representation of fuzzy numbers for linguistic variables of relative importance

The values of the criteria pair-wise comparison determine by decision maker are shown in Table 4.

Table 4

Linguistic assessment of criteria pair-wise comparison

\begin{tabular}{|c|c|c|c|c|c|c|c|c|c|c|c|c|c|c|c|c|c|c|}
\hline & $C_{1}$ & $\mathrm{C}_{11}$ & $\mathrm{C}_{12}$ & $\mathrm{C}_{13}$ & $\mathrm{C}_{2}$ & $\mathrm{C}_{21}$ & $\mathrm{C}_{22}$ & $\mathrm{C}_{23}$ & $\mathrm{C}_{3}$ & $\mathrm{C}_{31}$ & $\mathrm{C}_{32}$ & $\mathrm{C}_{4}$ & $\mathrm{C}_{41}$ & $\mathrm{C}_{42}$ & $\mathrm{C}_{43}$ & $\mathrm{C}_{5}$ & $\mathrm{C}_{51}$ & $\mathrm{C}_{52}$ \\
\hline$C_{1}$ & - & & & & $W M$ & & & & $A M$ & & & $W M$ & & & & $S M$ & & \\
\hline $\mathrm{C}_{11}$ & & - & SM & WM & & & & & & & & & & & & & & \\
\hline $\mathrm{C}_{12}$ & & $\mathrm{SL}$ & - & SL & & & & & & & & & & & & & & \\
\hline $\mathrm{C}_{13}$ & & WL & SM & - & & & & & & & & & & & & & & \\
\hline$C_{2}$ & $W L$ & & & & - & & & & $S M$ & & & $E$ & & & & $W M$ & & \\
\hline $\mathrm{C}_{21}$ & & & & & & - & SL & WL & & & & & & & & & & \\
\hline $\mathrm{C}_{22}$ & & & & & & SM & - & WM & & & & & & & & & & \\
\hline $\mathrm{C}_{23}$ & & & & & & WM & WL & - & & & & & & & & & & \\
\hline$C_{3}$ & $A L$ & & & & $S L$ & & & & - & & & $S L$ & & & & $W L$ & & \\
\hline $\mathrm{C}_{31}$ & & & & & & & & & & - & SM & & & & & & & \\
\hline $\mathrm{C}_{32}$ & & & & & & & & & & SL & - & & & & & & & \\
\hline$C_{4}$ & $W L$ & & & & $E$ & & & & $S M$ & & & - & & & & $W M$ & & \\
\hline $\mathrm{C}_{41}$ & & & & & & & & & & & & & - & SM & WM & & & \\
\hline $\mathrm{C}_{42}$ & & & & & & & & & & & & & SL & - & E & & & \\
\hline $\mathrm{C}_{43}$ & & & & & & & & & & & & & WL & E & - & & & \\
\hline$C_{5}$ & $S L$ & & & & $W L$ & & & & $W M$ & & & $W L$ & & & & - & & \\
\hline $\mathrm{C}_{51}$ & & & & & & & & & & & & & & & & & - & WL \\
\hline $\mathrm{C}_{52}$ & & & & & & & & & & & & & & & & & WM & - \\
\hline
\end{tabular}


Step 2. The importance weights of criteria is calculated in two phases: using Eq. (2) local weight of all criteria, $w_{i}$, are calculated and, latter, global weights of criteria, $W_{j}$, are derived by using Eq. (4). Local weights and global weights of criteria are shown in Table 5.

Table 5

Local weight and global weight of criteria

\begin{tabular}{llll}
\hline \multicolumn{2}{c}{ Criteria } & \multicolumn{1}{c}{$\mathrm{w}$} & \multicolumn{1}{c}{$\mathrm{W}$} \\
\hline $\mathrm{C}_{1}$ & & $(0.49,0.52,0.55)$ & \\
& $\mathrm{C}_{11}$ & $(0.52,0.61,0.65)$ & $(0.25,0.31,0.35)$ \\
& $\mathrm{C}_{12}$ & $(0,0.05,0.09)$ & $(0,0.03,0.05)$ \\
& $\mathrm{C}_{13}$ & $(0.24,0.29,0.37)$ & $(0.12,0.15,0.20)$ \\
$\mathrm{C}_{2}$ & & $(0.12,0.19,0.25)$ & \\
& $\mathrm{C}_{21}$ & $(0.04,0.1,0.14)$ & $(0.01,0.02,0.04)$ \\
& $\mathrm{C}_{22}$ & $(0.51,0.59,0.63)$ & $(0.06,0.11,0.16)$ \\
& $\mathrm{C}_{23}$ & $(0.19,0.25,0.33)$ & $(0.02,0.05,0.08)$ \\
$\mathrm{C}_{3}$ & & $(0,0.04,0.07)$ & \\
& $\mathrm{C}_{31}$ & $(0.7,0.85,1)$ & $(0,0.03,0.07)$ \\
& $\mathrm{C}_{32}$ & $(0,0.15,0.3)$ & $(0,0.01,0.02)$ \\
$\mathrm{C}_{4}$ & & $(0.14,0.18,0.2)$ & \\
& $\mathrm{C}_{41}$ & $(0.55,0.69,0,83)$ & $(0.05,0.12,0.17)$ \\
& $\mathrm{C}_{42}$ & $(0.020 .10 .19)$ & $(0,0.02,0.04)$ \\
& $\mathrm{C}_{43}$ & $(0.11,0.21,0.32)$ & $(0.01,0.04,0.06)$ \\
$\mathrm{C}_{5}$ & & $(0.02,0.06,0.09)$ & \\
& $\mathrm{C}_{51}$ & $(0.1,0.3,0.5)$ & $(0.01,0.02,0.05)$ \\
& $\mathrm{C}_{52}$ & $(0.5,0.7,0.9)$ & $(0.01,0.04,0.08)$ \\
\hline
\end{tabular}

Step 3. To evaluate the rating of the candidates with respect to each criterion, two evaluation systems are defined: using real numbers when criterion has quantitative dimension or using linguistic terms when criterion has qualitative dimension. In this latter case, five linguistic terms are used to measure the level of performance of each contractor with respect to each qualitative criterion. These linguistic terms are defined in Table 6.

Table 6

Evaluation levels of qualitative criteria

\begin{tabular}{lccccc}
\hline Qualitative sub-criteria & Level 1 & Level 2 & Level 3 & Level 4 & Level 5 \\
\hline Qualification of personnel & Very limited & Limited & Adequate & Excess & Great excess \\
Construction method & Inadequate & Adequate & Good & Very good & $\begin{array}{c}\text { Excellent } \\
\text { More than } \\
\text { enough }\end{array}$ \\
Sibor and equipment & Not enough & $\begin{array}{c}\text { Probably not } \\
\text { enough }\end{array}$ & $\begin{array}{c}\text { Almost } \\
\text { enough }\end{array}$ & Enough & Hoject completed \\
Type of project completed & Very low & Low & Moderate & High & Very high \\
& Absolutely & Not very & Similar & Quite similar & Exact \\
Organizational culture & None & Some & Enough & Almost all & All \\
Management knowledge & Inadequate & Adequate & Good & Very good & Excellent \\
Financial soundness & Very low & Low & Average & High & Very high \\
\hline
\end{tabular}

Each linguistic term is associated with a triangular fuzzy number as shown in Table 7 and Fig. 5. Neither it is possible to operate mathematically with a mixture of real and fuzzy numbers. To cope with this difficulty, real numbers are also transformed into triangular fuzzy number [38, 39]. For example, the crisp number 3 can be represented by triangular fuzzy number $(3.0,3.0$, $3.0)$. 
Table 7

Linguistic scale for rating of contractors

\begin{tabular}{ll}
\hline Linguistic set & Fuzzy number \\
\hline Level 1 & $(0,0,0.2)$ \\
Level 2 & $(0.1,0.25,0.4)$ \\
Level 3 & $(0.3,0.5,0.7)$ \\
Level 4 & $(0.6,0.75,0.9)$ \\
Level 5 & $(0.8,1.0,1.0)$ \\
\hline
\end{tabular}

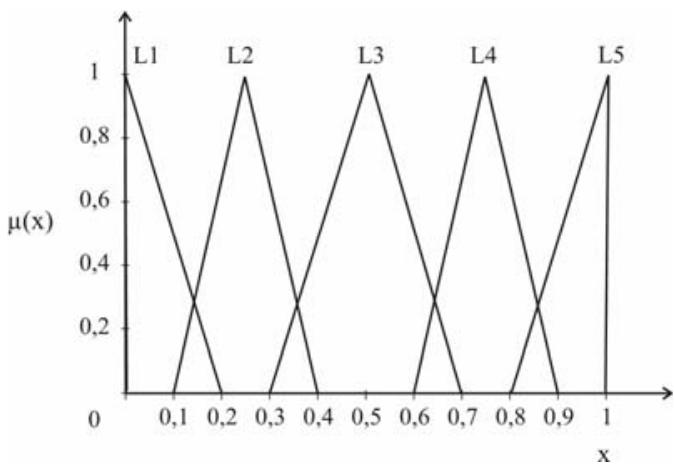

Fig. 5. Graphical representation of fuzzy numbers for linguistic variables of rating of contactors

The ratings of the five candidates under the various decision criteria are shown in Table 8 .

Table 8

Decision matrix

\begin{tabular}{|c|c|c|c|c|c|}
\hline & A & B & $\mathrm{C}$ & D & E \\
\hline $\mathrm{C}_{11}$ & $\begin{array}{c}\text { Adequate } \\
(0.3,0.5,0.7)\end{array}$ & $\begin{array}{c}\text { Excess } \\
(0.6,0.75,0.9)\end{array}$ & $\begin{array}{c}\text { Limited } \\
(0.1,0.25,0.4)\end{array}$ & $\begin{array}{c}\text { Adequate } \\
(0.3,0.5,0.7)\end{array}$ & $\begin{array}{l}\text { Great excess } \\
(0.8,1.0,1.0)\end{array}$ \\
\hline $\mathrm{C}_{12}$ & $\begin{array}{c}\text { Very good } \\
(0.6,0.75,0.9)\end{array}$ & $\begin{array}{c}\text { Good } \\
(0.3,0.5,0.7)\end{array}$ & $\begin{array}{c}\text { Good } \\
(0.3,0.5,0.7)\end{array}$ & $\begin{array}{c}\text { Very good } \\
(0.6,0.75,0.9)\end{array}$ & $\begin{array}{c}\text { Very good } \\
(0.6,0.75,0.9)\end{array}$ \\
\hline $\mathrm{C}_{13}$ & $\begin{array}{c}\text { Probably not enough } \\
(0.1,0.25,0.4)\end{array}$ & $\begin{array}{c}\text { Not enough } \\
(0,0,0.2)\end{array}$ & $\begin{array}{l}\text { More than enough } \\
(0.8,1.0,1.0)\end{array}$ & $\begin{array}{l}\text { More than enough } \\
(0.8,1.0,1.0)\end{array}$ & $\begin{array}{c}\text { Almost enough } \\
(0.3,0.5,0.7)\end{array}$ \\
\hline $\mathrm{C}_{21}$ & $\begin{array}{c}\text { Low } \\
(0.1,0.25,0.4)\end{array}$ & $\begin{array}{c}\text { Low } \\
(0.1,0.25,0.4)\end{array}$ & $\begin{array}{c}\text { Moderate } \\
(0.3,0.5,0.7)\end{array}$ & $\begin{array}{c}\text { High } \\
(0.6,0.75,0.9)\end{array}$ & $\begin{array}{l}\text { Very low } \\
(0,0,0.2)\end{array}$ \\
\hline $\mathrm{C}_{22}$ & $\begin{array}{c}\text { Similar } \\
(0.3,0.5,0.7)\end{array}$ & $\begin{array}{l}\text { Quite similar } \\
(0.6,0.75,0.9)\end{array}$ & $\begin{array}{l}\text { Quite similar } \\
(0.6,0.75,0.9)\end{array}$ & $\begin{array}{l}\text { Not very similar } \\
(0.1,0.25,0.4)\end{array}$ & $\begin{array}{c}\text { Not very similar } \\
(0.1,0.25,0.4)\end{array}$ \\
\hline $\mathrm{C}_{23}$ & $\begin{array}{c}10 \\
0.67\end{array}$ & $\begin{array}{c}7 \\
0.47\end{array}$ & $\begin{array}{c}9 \\
0.6\end{array}$ & $\begin{array}{c}13 \\
0.87\end{array}$ & $\begin{array}{l}15 \\
1.00\end{array}$ \\
\hline $\mathrm{C}_{31}$ & $\begin{array}{c}\text { Enough } \\
(0.3,0.5,0.7)\end{array}$ & $\begin{array}{c}\text { Almost all } \\
(0.6,0.75,0.9)\end{array}$ & $\begin{array}{c}\text { Some } \\
(0.1,0.25,0.4)\end{array}$ & $\begin{array}{c}\text { Almost all } \\
(0.6,0.75,0.9)\end{array}$ & $\begin{array}{c}\text { Enough } \\
(0.3,0.5,0.7)\end{array}$ \\
\hline $\mathrm{C}_{32}$ & $\begin{array}{c}\text { Very good } \\
(0.6,0.75,0.9)\end{array}$ & $\begin{array}{c}\text { Good } \\
(0.3,0.5,0.7)\end{array}$ & $\begin{array}{c}\text { Adequate } \\
(0.1,0.25,0.4)\end{array}$ & $\begin{array}{c}\text { Good } \\
(0.3,0.5,0.7)\end{array}$ & $\begin{array}{c}\text { Good } \\
(0.3,0.5,0.7)\end{array}$ \\
\hline $\mathrm{C}_{41}$ & $\begin{array}{c}1 \\
1.00\end{array}$ & $\begin{array}{c}1 \\
1.00\end{array}$ & $\begin{array}{c}2 \\
0.50\end{array}$ & $\begin{array}{c}3 \\
0.33\end{array}$ & $\begin{array}{c}2 \\
0.50\end{array}$ \\
\hline $\mathrm{C}_{42}$ & $\begin{array}{c}1 \\
1.00\end{array}$ & $\begin{array}{c}2 \\
0.50\end{array}$ & $\begin{array}{c}1 \\
1.00\end{array}$ & $\begin{array}{c}2 \\
0.50\end{array}$ & $\begin{array}{c}4 \\
0.25\end{array}$ \\
\hline $\mathrm{C}_{43}$ & $\begin{array}{c}2 \\
0.50\end{array}$ & $\begin{array}{c}1 \\
1.00\end{array}$ & $\begin{array}{c}3 \\
0.33\end{array}$ & $\begin{array}{c}2 \\
0.50\end{array}$ & $\begin{array}{c}3 \\
0.33\end{array}$ \\
\hline $\mathrm{C}_{51}$ & $\begin{array}{c}\text { High } \\
(0.6,0.75,0.9)\end{array}$ & $\begin{array}{c}\text { Average } \\
(0.3,0.5,0.7)\end{array}$ & $\begin{array}{c}\text { Average } \\
(0.3,0.5,0.7)\end{array}$ & $\begin{array}{c}\text { High } \\
(0.6,0.75,0.9)\end{array}$ & $\begin{array}{l}\text { Very low } \\
(0,0,0.2)\end{array}$ \\
\hline $\mathrm{C}_{52}$ & $\begin{array}{c}€ 7 \mathrm{M} \\
0.50\end{array}$ & $\begin{array}{c}€ 10 \mathrm{M} \\
0.72\end{array}$ & $\begin{array}{c}€ 14 \mathrm{M} \\
1.00\end{array}$ & $\begin{array}{c}€ 11 \mathrm{M} \\
0.79\end{array}$ & $\begin{array}{c}€ 6 \mathrm{M} \\
0.43\end{array}$ \\
\hline
\end{tabular}

Step 4. The normalized fuzzy decision matrix is constructed using Eqs. (5) and (7) as shown in Table 8. 
Step 5. Weighted normalized fuzzy decision matrix is constructed using Eq. (9) as shown in Table 9.

Table 9

Decision matrix

\begin{tabular}{cccccc}
\hline & $\mathrm{A}$ & $\mathrm{B}$ & $\mathrm{C}$ & $\mathrm{D}$ & $\mathrm{E}$ \\
\hline $\mathrm{V}_{11}$ & $(0.08,0.16,0.25)$ & $(0.15,0.23,0.32)$ & $(0.03,0.08,0.14)$ & $(0.08,0.16,0.25)$ & $(0.20,0.31,0.35)$ \\
$\mathrm{V}_{12}$ & $(0.000 .02,0.05)$ & $(0.00,0.02,0.04)$ & $(0.00,0.02,0.04)$ & $(0.00,0.02,0.05)$ & $(0.00,0.02,0.05)$ \\
$\mathrm{V}_{13}$ & $(0.01,0.04,0.08)$ & $(0.00,0.00,0.04)$ & $(0.07,0.11,0.18)$ & $(0.10,0.15,0.20)$ & $(0.04,0.08,0.14)$ \\
$\mathrm{V}_{21}$ & $(0.00,0.01,0.02)$ & $(0.00,0.01,0.02)$ & $(0.00,0.01,0.03)$ & $(0.01,0.02,0.049$ & $(0.00,0.00,0.01)$ \\
$\mathrm{V}_{22}$ & $(0.02,0.06,0.11)$ & $(0.04,0.08,0.14)$ & $(0.02,0.06,0.11)$ & $(0.01,0.03,0.06)$ & $(0.01,0.03,0.06)$ \\
$\mathrm{V}_{23}$ & $(0.01,0.03,0.05)$ & $(0.01,0.02,0.04)$ & $(0.01,0.03,0.05)$ & $(0.02,0.04,0.07)$ & $(0.02,0.05,0.08)$ \\
$\mathrm{V}_{31}$ & $(0.00,0.02,0.05)$ & $(0.00,0.02,0.06)$ & $(0.00,0.01,0.03)$ & $(0.00,0.02,0.06)$ & $(0.00,0.02,0.05)$ \\
$\mathrm{V}_{32}$ & $(0.00,0.01,0.02)$ & $(0.00,0.01,0.01)$ & $(0.00,0.00,0.01)$ & $(0.00,0.01,0.01)$ & $(0.00,0.01,0.01)$ \\
$\mathrm{V}_{41}$ & $(0.05,0.12,0.17)$ & $(0.05,0.12,0.17)$ & $(0.03,0.06,0.09)$ & $(0.02,0.04,0.06)$ & $(0.03,0.06,0.09)$ \\
$\mathrm{V}_{42}$ & $(0.00,0.02,0.04)$ & $(0.00,0.01,0.02)$ & $(0.00,0.02,0.03)$ & $(0.00,0.01,0.02)$ & $(0.00,0.01,0.01)$ \\
$\mathrm{V}_{43}$ & $(0.01,0.02,0.03)$ & $(0.01,0.04,0.06)$ & $(0.00,0.01,0.02)$ & $(0.01,0.02,0.03)$ & $(0.00,0.01,0.02)$ \\
$\mathrm{V}_{51}$ & $(0.01,0.02,0.05)$ & $(0.00,0.01,0.04)$ & $(0.00,0.01,0.04)$ & $(0.01,0.02,0.05)$ & $(0.00,0.00,0.01)$ \\
$\mathrm{V}_{52}$ & $(0.01,0.02,0.04)$ & $(0.01,0.03,0.06)$ & $(0.01,0.04,0.08)$ & $(0.01,0.03,0.06)$ & $(0.00,0.02,0.03)$ \\
\hline
\end{tabular}

Step 6. Calculate the closeness coefficient of each supplier using Eq. (10) as shown in Table 10.

Table 10

Values of $d^{*}, d^{-}$and CC of each contractor

\begin{tabular}{cccc}
\hline Contractor & $\mathrm{d}^{*}$ & $\mathrm{~d}^{-}$ & $\mathrm{CC}$ \\
\hline A & 0.1808 & 0.1283 & 0.5848 \\
B & 0.1591 & 0.1880 & 0.4583 \\
C & 0.2302 & 0.1240 & 0.6499 \\
D & 0.1718 & 0.1686 & 0.5046 \\
E & 0.1202 & 0.2298 & 0.3434 \\
\hline
\end{tabular}

Step 7. Three classes of assessment status of contractors are defined as shown in Table 11. It means that

- If $C C_{i} \in[0,0.4)$ then contractor $\mathrm{A}_{\mathrm{i}}$ belong to Class I and the assessment status of contactor $A_{i}$ is "not recommended".

- If $C C_{i} \in[0.4,0.6)$ then contractor $\mathrm{A}_{\mathrm{i}}$ belong to Class II and the assessment status of contactor $A_{i}$ is "recommended with risk".

- If $C C_{i} \in[0.6,1]$ then contractor $\mathrm{A}_{\mathrm{i}}$ belong to Class III and the assessment status of contactor Ai is "approved".

Table 11

Classification rules

\begin{tabular}{ll}
\hline Closeness coefficient $\left(\mathrm{CC}_{\mathrm{i}}\right)$ & Assessment status \\
\hline $\mathrm{CC}_{\mathrm{i}} \in[0,0.4)$ & Do not recommended \\
$\mathrm{CC}_{\mathrm{i}} \in[0.4,0.6)$ & Recommended with risk \\
$\mathrm{CC}_{\mathrm{i}} \in[0.6,1]$ & Approved \\
\hline
\end{tabular}

Step 8. According to the closeness coefficients of the five contractors and the defined status level, contractor E belongs to Class I, what means that its assessment status is "Do not recommended". Contractors A, B and D belong to Class II, what means that their assessment status is "Recommended with risk". Finally, Contractor C belongs to Class III, what means that its assessment status is "Approved". 
However, according to the closeness coefficients contractor A is preferred to contractors $\mathrm{D}$ and $\mathrm{B}$, and contractor $\mathrm{D}$ is preferred to contactor $\mathrm{B}$ in Class II because $\mathrm{CC}_{\mathrm{A}}>\mathrm{CC}_{\mathrm{D}}>\mathrm{CC}_{\mathrm{B}}$. Therefore, the ranking order of the five contractors is $\mathrm{C}>\{\mathrm{A}>\mathrm{D}>\mathrm{B}\}>\mathrm{E}$.

\section{Conclusions}

The success level of any construction project depends significantly on the selection of an adequate contractor. Contractor prequalification is a widely used process to select responsible and competent contractors to undertake the construction contract and deliver optimal results with minimal failures. Contractor prequalification can be regarded as a multi-criteria decision problem since potential contractors are measured and judged in accordance with a common set of criteria.

Most of real-world prequalification problems involve uncertainty and imprecision in the estimates of performance ratings and criteria weights due to the own nature of construction projects and subjectivity of decision-makers' judgements. In this decision environment, it is too complex to reasonably describe the problem by conventional quantitative expressions; therefore it is more adequate to express decision-makers' judgments in qualitative form than quantitative one. Fuzzy Set Theory is an adequate tool to deal with vague, imprecise and uncertain problems by using the concept of linguistic variable, which is a variable whose values are words or sentences in a natural language instead, numerical values.

In this paper, a contractor prequalification model, based on Fuzzy Set Theory, is presented. The advantages of this method, compared with other available prequalification methods, can be summarised as follows:

1. A hierarchical structure of criteria is generated to facilitate the process for assessing the weights of criteria.

2. Criteria weights are calculate from comparative judgement of criteria pair-wise which are expressed in linguistic terms. An algorithm to handle the inconsistencies in the fuzzy preference relation has been implemented.

3. The performance value of each contractor on each criterion is defined in exact numerical values or in linguistic terms if the criterion is quantitative or qualitative, respectively.

4. The implemented algorithm does not require cumbersome computations; however computational procedure has been programmed by MATLAB in order to solve the problem in a shorter and more accurate way.

The proposed model is not intended to supplant the work of decision-making teams in the prequalification process, but rather to help them make quality evaluations of the available candidate contractors.

The proposed method provides a systematic framework for contractor prequalification in a fuzzy environment that can be easily extended to the analysis of other classification problems in project management. However, improving the approach for solving contractor prequalification problems more efficiently and developing a group decision support system can be considered as a topic for future research.

Appendix A. The algebraic operations of fuzzy numbers based on $\alpha$-cut concept.

The $\alpha$-cuts of a fuzzy number $A$ with membership function $\mu_{A}(x)$ are the crisp set:

$\mathrm{A}^{\alpha}=\left\{\mathrm{x} \mid \mu_{\mathrm{A}}(\mathrm{x}) \geq \alpha, 0 \geq \alpha \geq 1\right\}$

denoted by the closed interval $\left[{ }^{L} A^{\alpha},{ }^{R} A^{\alpha}\right]$.

Property 1 [32]. An arbitrary fuzzy number A can fully and uniquely be represented as:

$$
\mathrm{A}=\bigcup_{\alpha \in[0,1]}{ }^{\alpha} \mathrm{A}^{\alpha}(\mathrm{x})
$$

where $U$ denotes the standard fuzzy union and $\alpha \_A^{\alpha}$ denotes the special fuzzy set which membership function is defined as: 


$$
\mu_{\alpha \_A_{\alpha}}= \begin{cases}\alpha & \text { for } \mathrm{x} \in \mathrm{A}^{\alpha} \\ 0 & \text { for } \mathrm{x} \notin \mathrm{A}^{\alpha}\end{cases}
$$

Property 2 [32]. Given two positive fuzzy numbers $A$ and $B$, which $\alpha$-cuts are denoted as $A^{\alpha}=\left[{ }^{L} A^{\alpha},{ }^{R} A^{\alpha}\right]$ and $B^{\alpha}=\left[{ }^{L} B^{\alpha},{ }^{R} B^{\alpha}\right]$ respectively, four main operations of these two fuzzy numbers can be expressed as follow:

Addition of two trapezoidal fuzzy numbers $\oplus$

$$
\mathrm{A} \oplus \mathrm{B}=\underset{\alpha \in[0,1]}{\bigcup_{-}-\left(\left[{ }^{\mathrm{L}} \mathrm{A}^{\alpha}+{ }^{\mathrm{L}} \mathrm{B}^{\alpha},{ }^{\mathrm{R}} \mathrm{A}^{\alpha}+{ }^{\mathrm{R}} \mathrm{B}^{\alpha}\right]\right)}
$$

Subtraction of two trapezoidal fuzzy numbers $\Theta$

$$
\mathrm{A} \Theta \mathrm{B}=\underset{\alpha \in[0,1]}{\bigcup_{-}-\left(\left[\mathrm{A}^{\alpha}-{ }^{\mathrm{R}} \mathrm{B}^{\alpha},{ }^{\mathrm{R}} \mathrm{A}^{\alpha}-{ }^{\mathrm{L}} \mathrm{B}^{\alpha}\right]\right)}
$$

Multiplication of two trapezoidal fuzzy numbers $\otimes$

$$
\mathrm{A} \otimes \mathrm{B}=\underset{\alpha \in[0,1]}{\bigcup_{-}-\left(\left[{ }^{\mathrm{L}} \mathrm{A}^{\alpha} \times{ }^{\mathrm{L}} \mathrm{B}^{\alpha},{ }^{\mathrm{R}} \mathrm{A}^{\alpha} \times{ }^{\mathrm{R}} \mathrm{B}^{\alpha}\right]\right)}
$$

Division of two trapezoidal fuzzy numbers $\emptyset$

$$
\left.\left.\mathrm{A} \emptyset \mathrm{B}=\underset{\alpha \in[0,1]}{\bigcup_{-}-\left(\left[\mathrm{A}^{\alpha} / \mathrm{R}\right.\right.} \mathrm{B}^{\alpha},{ }^{\mathrm{R}} \mathrm{A}^{\alpha} / \mathrm{L} \mathrm{B}^{\alpha}\right]\right)
$$

Property 3 [40]. Given two positive fuzzy numbers $A$ and $B$, which $\alpha$-cuts are denoted as $A^{\alpha}=\left[{ }^{L} A^{\alpha},{ }^{R} A^{\alpha}\right]$ and $B^{\alpha}=\left[{ }^{L} B^{\alpha},{ }^{R} B^{\alpha}\right]$ respectively, the distance between them is calculated as:

$$
\mathrm{d}_{v}(\mathrm{~A}, \mathrm{~B})=\sqrt{\frac{1}{\mathrm{n}} \sum_{\alpha=0}^{1} \mathrm{~d}^{2}\left(\mathrm{~A}^{\alpha}, \mathrm{B}^{\alpha}\right)}
$$

where $n$ is the number of $\alpha$-cuts defined for $A$ and $B$ and the distance between $\alpha$-cuts is defined as:

$$
\mathrm{d}^{2}\left(\mathrm{~A}^{\alpha}, \mathrm{B}^{\alpha}\right)=\frac{1}{2}\left[\left({ }^{\mathrm{L}} \mathrm{A}^{\alpha}-{ }^{\mathrm{L}} \mathrm{B}^{\alpha}\right)^{2}+\left({ }^{\mathrm{R}} \mathrm{A}^{\alpha}-{ }^{\mathrm{R}} \mathrm{B}^{\alpha}\right)^{2}\right]
$$

\section{References}

[1] K.C. Lam, E. Palaneeswaran, C. Yu, A support vector machine model for contractor prequalification, Automation in Construction 18 (3) (2009) 321-329.

[2] D.J. Watt, B. Kayis, K. Willey, The relative importance of tender evaluation and contractor selection criteria, International Journal of Project Management 28 (1) (2010) 51-60.

[3] E. Palaneeswaran, M. Kumaraswamy, Recent advances and proposed improvements in contractor pre-qualification methodologies, Building and Environment 36 (1) (2001) 73-87.

[4] Z. Hatush, M. Skitmore, Contractor selection using multi-criteria utility theory: An additive model, Building and Environment 33 (2) (1998) 105-1 15.

[5] E.K. Zavadskas, T. Vilutiene, A multiple criteria evaluation of multi-family apartment block's maintenance contractors: I-Model for maintenance contractor evaluation and the determination of its selection criteria, Building and Environment 41 (5) (2006) 621-632.

[6] N. El-Sawalhi, D. Eaton, R. Rustom, Contractor prequalification model: State-of-the-art, International Journal of Project Management 25 (5) (2007) 465-474.

[7] I.M. Mahdi, M.J. Riley, S.M. Fereig, A.P. Alex, A multi-criteria approach to contractor selection, Engineering, Construction and Architectural Management 9 (1) (2002) 29-37.

[8] E.W.L. Cheng, H. Li, Contractor selection using the analytic network process, Construction Management and Economics 22(10) (2004) 1021-32.

[9] O. Abudayyeh, S.J. Zidan, S. Yehia, D. Randolph, Hybrid Prequalification-Based, Innovative Contracting Model Using AHP, Journal of Management in Engineering 23 (2) (2007) 88-96.

[10] G.D. Holt, P.O. Olomolaiye, F.D. Harris, Evaluating pre-qualification criteria in contractor selection, Building and Environment 29 (4) (1994) 437-48. 
[11] Y.I. Topcu, A decision model proposal for construction contractor selection in Turkey, Building and Environment 39(4) (2004) 469-81.

[12] C.H. Wong, J. Nicholas, G.D. Holt, Using multivariate techniques for developing contractor classification models, Engineering, Construction and Architectural Management 10 (2) (2003) 99116.

[13] S.T. Ng, EQUAL: a case-based contractor prequalifier, Automation in Construction 10 (4) (2001) $443-457$.

[14] Y.K. Juan, A hybrid approach using data envelopment analysis and case-based reasoning for housing refurbishment contractors selection and performance improvement, Expert Systems with Applications 36 (3) (2009) 5702-5710.

[15] G.D. Holt, Applying Cluster Analysis to Construction Contractor Classification, Building and Environment 31 (6) (1996) 557-568.

[16] M. Darvish, M. Yasaei, A. Saeedi, Application of the graph theory and matrix methods to contractor ranking, International Journal of Project Management 27(6) (2009) 610-619.

[17] L.A. Zadeh, Fuzzy sets, Information and control 8 (3) (1965) 338-353.

[18] L.A. Zadeh, The concept of a linguistic variable and its application to approximate reasoning, Information Sciences 8 (3) (1975) 199-249.

[19] V. U. Nguyen, Tender evaluation by fuzzy sets, Journal of Construction Engineering and Management 111 (3) (1985) 231-243.

[20] K. C. Lam, T. Hu, S. Thomas, Ng, M. Skitmore, S.O. Cheung, A fuzzy neural network approach for contractor prequalification, Construction Management and Economics 19 (2) (2001)175-188.

[21] D. Singh, R.L.K. Tiong, A fuzzy decision framework for contractor selection, Journal of Construction Engineering and Management 131(1) (2005) 62-70.

[22] Y. Li, X. Nie, S. Chen, Fuzzy approach to prequalifying construction contractors, Journal of Construction Engineering and Management 133 (1) (2007) 40-49.

[23] E. Plebankiewicz, Contractor prequalification model using fuzzy sets, Journal of civil engineering and management 15(4) (2009) 377-385.

[24] Y.K. Juan, Y.H. Perng, D. Castro-Lacouture, K.S. Lu, Housing refurbishment contractors selection based on a hybrid fuzzy-QFD approach, Automation in Construction 18 (2) (2009) 139-144.

[25] S.T. Ng, R.M. Skitmore, Client and consultant perspectives of prequalification criteria, Building and Environment 34 (5) (1999) 607-621

[26] S.T. Ng, S. Thomas, R.M. Skitmore, CP-DSS: Decision support system for contractor prequalification, Civil Engineering and Environmental Systems 12 (2) (1995) 133-159.

[27] Hatush, M. Skitmore, Criteria for contractor selection, Construction Management and Economics 15 (1) (1997) 19-38.

[28] G. Arslan, S. Kivrak, M.T. Birgonul, I. Dikmen, Improving sub-contractor selection process in construction projects: Web-based sub-contractor evaluation system (WEBSES), Automation in Construction 17 (4) (2008) 480-488.

[29] P. Jaskowski, S. Biruk, R. Bucon, Assessing contractor selection criteria weights with fuzzy AHP method application in group decision environment, Automation in Construction 19 (2) (2010) 120126.

[30] G. Mayor, E. Trillas, On the representation of some aggregation functions, Proceedings 16th ISMVL, Blacksburg, (1986) 110-114.

[31] D. Dubois, H. Prade, Operations on fuzzy numbers, International Journal of Systems Science 9 (6) (1978) 613-626.

[32] J.K. Klir, B. Yuan, Fuzzy sets and fuzzy logic. Theory and applications, Prentice Hall, New Jersey, 1995.

[33] J. Ma, Z.P. Fan, Y.P. Jiang, J.Y. Mao, A method for repairing the inconsistency of fuzzy preference relations, Fuzzy sets and systems 157 (1) (2006) 20-33.

[34] T.C. Wang, Y.H. Chen, Applying fuzzy linguistic preference relations to the improvement of consistency of fuzzy AHP, Information Sciences 178 (19) (2008) 3755-3765.

[35] W. Dong, H.C. Shah, Vertex methods for computing functions of fuzzy variable, Fuzzy Sets and Systems 24 (1) (1987) 65-78.

[36] E. Herrera-Viedma, F. Herrera, F. Chiclana, M. Luque, Some issues on consistency of fuzzy preference relations, European Journal of Operational Research 154 (1) (2004) 98-109.

[37] C.L. Hwang, C.C. Yoon, Multiple attribute decision making: Methods and applications, Berlin: Spriger, 1981.

[38] G.S. Liang, Fuzzy MCDM based on ideal and anti-ideal concepts, European Journal of Operational Research 112 (3) (1999) 682-691. 
[39] H.J. Zimmermann, Fuzzy Set Theory and its Applications. Kluwer Academic Publishers: Boston, 2001.

[40] D. Dubois, H. Prade, Fuzzy Sets and Systems, Theory and Applications, Academic Press, New York, 1980. 